\title{
Entrevista \\ Com Prof. Joaquina Barata - Universidade Federal do Pará
}

[...]Era o tempo da guerra fria, em que o capitalismo competia com o socialismo. Como o socialismo promovia a planificação social, o capitalismo criava sistemas de bem-estar social, principalmente na Escandinávia.

\section{SS\&S - Prof. ${ }^{\text {a }}$ MSc. Joaquina Barata, a senhora poderia nos contar como foi seu encontro com o Serviço Social?}

Prof. ${ }^{a}$ Joaquina - Estava terminando o ensino médio no Instituto de Educação do Pará, quando fui indicada por uma grande colega chamada Elizabeth Santos (por solicitação de um professor de Psicologia de nossa turma), para um curso a ser feito no Rio de Janeiro. Ele era Diretor do SESC (Serviço Social do Comércio). Se eu fizesse o curso, ganharia um emprego, com trabalho na área da recreação infantil, destinado a crianças filhas e filhos dos comerciários. Era o tempo da guerra fria, em que o capitalismo competia com o socialismo. Como o socialismo promovia a planificação social, o capitalismo criava sistemas de bem-estar social, principalmente na Escandinávia. No Brasil não foi criado, à época, nenhum sistema de Proteção Social, mas organizações patronais como SESC, SENAI, SESI e SENAC ensaiavam um arremedo de proteção privada às famílias dos trabalhadores da indústria e do comércio.

Nesse curso, conheci admiráveis assistentes sociais que já eram famosas no Brasil, entre elas Edith Mota, por quem tive enorme admiração, por sua educação refinadíssima e sua competência profissional. No SESC passei a conviver com assistentes sociais, entre as quais diretoras e professoras do Curso de Serviço Social (que já havia sido criado em Belém). Vislumbrei nessa nascente profissão possibilidades que na época estavam mais em minha

\footnotetext{
${ }^{1}$ Cursou Serviço Social na Universidade Federal do Pará (1963) e concluiu Mestrado em Planejamento do Desenvolvimento (1985). Exerceu o magistério no Curso de Serviço Social da UFPA no período de 1972 a 1996. Foi Pró-Reitora de Planejamento UFPA (1993-1997) e membro do Comitê Executivo da International Federation of Social Workers (Federação Internacional de Trabalhadores Sociais) em dois mandatos (2002 a 2005 e 2005 a 2008).

Serv. Soc. \& Saúde, Campinas, SP v. 13, n. 1 (17) p. 151-158 jan.jjun. 2014 ISSN 1676-6806
} 
[...] Foi uma luta vitoriosa e minha turma foi a primeira formada pela UFPA. Isso marcou o início de um envolvimento político, que passei a praticar em toda a vida estudantil e mais tarde profissional. imaginação do que no exercício profissional. O certo é que ingressei como aluna quando o curso ainda não era da Universidade, o que só veio a acontecer mais tarde, já por conta de uma luta política estudantil, que reuniu estudantes de Serviço Social e estudantes de Química. O Reitor de então não nos queria na Universidade. Foi uma luta vitoriosa e minha turma foi a primeira formada pela UFPA ${ }^{2}$. Isso marcou o início de um envolvimento político, que passei a praticar em toda a vida estudantil e mais tarde profissional. Começou aí a minha apropriação conceitual de uma teoria crítica e minha indignação ante uma estrutura hierarquizada de classes sociais, em que uma minoria detém o poder econômico, a propriedade, o prestígio, a renda e a riqueza ao lado de um grande contingente de pessoas que só contam com sua força de trabalho para conseguir o alimento e o abrigo.

SS\&S - A senhora é uma autoridade no campo do Serviço Social, cuja história está intimamente ligada ao processo de consolidação do Serviço Social no país. Gostaríamos que a senhora nos contasse sobre sua participação na ALAETS e de como se deu o processo de fortalecimento do Serviço Social no Brasil.

Prof. $^{\text {a }}$ Johquina - Na verdade quando assumi a responsabilidade por RI (Relações Internacionais) enquanto vicepresidente do CFESS (Conselho Federal de Serviço Social), a ALAETS $^{3}$ e o CELATS ${ }^{4}$, que eram formadores do pensamento acadêmico na América Latina e difundiam um Serviço Social Reconceituado na década de 1960, já tinham sido extintas (como um dos estragos das ditaduras na América Latina), e minha participação se deu no Comitê Mercosul, organização originada

\footnotetext{
${ }^{2}$ A primeira Escola de Serviço Social do Pará foi fundada em 10 de abril de 1950 e inaugurada a 15 de maio do mesmo ano. Foi a segunda na Região Amazônica (a primeira foi criada no Estado do Amazonas) e a $15^{\mathrm{a}}$ no país. Em 1954 foi regulamentada como ensino superior e reconhecida pelo MEC em 1957. Foi êncampada pela Universidade Federal do Pará em 1963.

${ }_{4}$ Associação Latino-americana de Trabalho Social

Centro Latino-americano de Trabalho Social

Serv. Soc. \& Saúde, Campinas, SP v. 13, n. 1 (17) p. 151-158 jan./jun. 2014 ISSN 1676-6806
} 


\section{[...] Considero a evolução do Comitê Mercosul para o COLACATS um processo de extraordinária importância. Significa que a entidade ultrapassou os limites geopolíticos do Cone Sul, e hoje ousa alcançar a América Latina e Caribe.}

do Tratado de Assunção de 1991, formado inicialmente apenas com países do Cone Sul (Argentina, Brasil e Uruguai), onde o tema da livre circulação de profissionais no Cone Sul (hoje um tema polêmico no Brasil), compareceu como pauta e este foi um dos motivos que pressionou, em 1995, em Montevidéu, o primeiro protocolo de intenções em que 03 organizações profissionais de Trabalhadores Sociais do Cone Sul se comprometeram a criar o Comitê Mercosul de Organizações Profissionais de Trabalho Social. O Comitê foi formalmente criado a 14 de março de 1996, incluindo depois o Paraguai e só em 2006 a Venezuela. Isto aconteceu na reunião do Comitê Mercosul realizada em Santiago do Chile, por ocasião do Congresso Mundial da AIETS (Associação Internacional de Escolas de Trabalho Social), em que Elizabete Borgianni e eu estivemos presentes. Tal Comitê evoluiu em 2013 para o hoje denominado Comitê Latino-americano e Caribenho de Organizações Profissionais de Trabalho Social/Serviço Social (COLACATS), com a participação de 12 países (Argentina, Brasil, Uruguai, Chile, Porto Rico, Costa Rica, Peru, Colômbia, República Dominicana, Nicarágua, México e Cuba) $)^{5}$.

Considero a evolução do Comitê Mercosul para o COLACATS um processo de extraordinária importância. Significa que a entidade ultrapassou os limites geopolíticos do Cone Sul, e hoje ousa alcançar a América Latina e Caribe.

No que diz respeito ao fortalecimento do Serviço Social no Brasil, vale chamar a atenção para o fato de que só no contexto

\footnotetext{
${ }^{5}$ Federación Argentina de Asociaciones Profesionales de Servicio Social (FAAPSS), 2. Conselho Federal de Serviço Social (CFESS), 3. Asociación de Asistentes Sociales del Uruguay (ADASU), 4. Colegio de Asistentes Sociales y Trabajadores Sociales de Chile (CTSC), 5. Colegio de Profesionales de Trabajo Social de Puerto Rico (CPTSPR), 6. Colegio de Trabajadores Sociales de Costa Rica (CTS), 7. Colegio de Trabajadores Sociales del Perú (CTSP), 8. Federación Colombiana de Trabajadores Sociales (FECTS), 9. Asociación Dominicana de Profesionales de Trabajo Social (ADOPTRASOC), 10. Asociación Nicaragüense de Trabajadores Sociales Mildred Abaunza (ANTS), 11. Asociación de Trabajadores Sociales Mexicanos A.C (ASMACT), 12. Sociedad Cubana de Trabajadores Sociales de la Salud (SOCUTRAS).

Serv. Soc. \& Saúde, Campinas, SP v. 13, n. 1 (17) p. 151-158 jan./jun. 2014 ISSN 1676-6806
} 


\section{[...] O Serviço Social também organizou-se em termos profissionais e políticos, de uma forma pouco vista, em âmbito local, regional, continental e mundial $[. .$.}

da redemocratização brasileira é que o Serviço Social retomou o seu movimento expansivo e ascendente que culmina nas seguintes conquistas:

1) No avanço extraordinário do universo conceitual e categorial da profissão, com a maioria de seus docentes procedendo rupturas no campo paradigmático com as vertentes conservadoras das Ciências Sociais, consagrando e consolidando essa ruptura no projeto pedagógico do curso, que passa a adotar a orientação das Diretrizes Curriculares em seu produto final, aprovado em uma Assembleia da ABEPSS.

2) Na intensificação da produção acadêmica que contribuiu para que o Serviço Social brasileiro passasse a ser reconhecido, a partir da década de 80, como um dinâmico campo de pesquisa, gerado não só na pós-graduação como na graduação e até no âmbito do exercício profissional. Como bem salientou Elizabete Borgianni (2006), expresidente do Conselho Federal de Serviço Social, em sua fala de abertura em Reunião Ampliada dos Conselhos dos dias 29 e 30/04/2007: “a produção acadêmica do Serviço Social brasileiro é hoje referência para os trabalhadores sociais da América Latina, de Portugal e dos países africanos de língua portuguesa”.

3) O Serviço Social também organizou-se em termos profissionais e políticos, de uma forma pouco vista, em âmbito local, regional, continental e mundial, tanto no campo da formação como no do exercício profissional, consolidando entidades que atuam de forma responsável e democrática, que são ativas, antenadas com o movimento político interno e externo.

4) No âmbito internacional do exercício profissional latinoamericano, foi uma conquista a presença de assistentes sociais brasileiros e latino-americanos no Comitê Executivo 
[...] São conquistas que não são triviais. Pelo contrário, resultam do amadurecimento conquistado em muitos anos de estudos e de luta. da FITS (com sede em Berna, na Suíça) por 09 anos.

5) Além das organizações próprias, assistentes sociais tiveram sua inserção na direção dos mais variados sindicatos, incluindo os sindicatos docentes da Universidade Federal do Pará e do ANDES, sindicato nacional, além de funções de comando e direção nos Institutos, nas Pró-Reitorias, nos Ministérios. Assistentes sociais graduados e pós-graduados estão envolvidos hoje nos mais variados espaços ocupacionais, como o do meio ambiente, o das etnias, o da questão agrária, o dos impactos sociais dos grandes projetos, da gestão de projetos, o do planejamento, o do controle social e o da gestão do trabalho.

6) Vemos como um avanço a declaração e adoção, por parte de nossas organizações, de um projeto ético-político profissional, vinculado geneticamente a uma proposta de transformação social e de um projeto societário comprometido com a emancipação humana.

São conquistas que não são triviais. Pelo contrário, resultam do amadurecimento conquistado em muitos anos de estudos e de luta.

\section{SS\&S - Quais são os principais desafios postos à profissão na contemporaneidade?}

Prof. ${ }^{a}$ JoAquina - Diria, sem medo de exagerar, com base nos enfrentamentos do Serviço Social no mundo inteiro, que vivemos tempos altamente desafiadores para os Direitos Humanos e para o exercício profissional dos/as assistentes sociais, porque são tempos que simbolizam, para os seres humanos, especialmente para as classes trabalhadoras e subalternizadas, muito do que há de trágico, de dramático, de agourento e ameaçador na vida.

Assistentes sociais do oriente médio e da África, atuam em "atrocidades que deveriam enfurecer a consciência de 
[...]Vale lembrar o inferno dos abrigos e das prisões, onde o estupro e a tortura subsistem e os gestores fingem que não sabem. humanidade” em dolorosas situações decorrentes das guerras, vendo crianças sequestradas, violentamente recrutadas para o combate, separadas de suas famílias, além das sexualmente exploradas. Na América Latina, as/os assistentes sociais trabalham, hoje, com imensos contingentes aos quais são negados direitos básicos, mesmo nos países em que esses direitos já se encontram formulados nas Constituições, como é o caso do Brasil. Cabe-nos lembrar os vergonhosos trabalho escravo e trabalho infantil, onde a região amazônica detém casos escandalosos. Em muitos países ainda existe a pena de morte, que é uma confissão do fracasso da universalização e concretização dos Direitos Humanos. Vale lembrar o inferno dos abrigos e das prisões, onde o estupro e a tortura subsistem e os gestores fingem que não sabem. Temos que lembrar ainda as nossas crianças indígenas, morrendo de fome cotidianamente enquanto suas culturas, terras e modo de vida são destruídos por latifundiários, madeireiros e grileiros, os quais impõem os seus interesses a bala, além de outras situações que tornam a violação aos Direitos Humanos uma violação coletiva e às vezes torna sujeito da violação o próprio Estado que deveria assegurar direitos.

SS\&S - Finalizando a entrevista, agradecemos sua disponibilidade e a convidamos a deixar uma mensagem aos leitores da Revista?

Prof. ${ }^{a}$ Joaquina - Minha mensagem expõe o que sempre acreditei (o que pode até ser considerada uma perspectiva visionária): a de que o Serviço Social pode dar uma resoluta contribuição à história do ponto de vista do trajeto para a emancipação humana, quer seja no ensino, na pesquisa, na extensão e no exercício profissional (no SUS, no SUAS, na FUNAI, na Previdência, ou em todas as outras políticas em que a profissão atua). Nossa profissão está mergulhada num embate ético-político e temos que tomar partido a favor da transformação 
social. Não desanimemos. Estamos sempre num combate, em uma luta e precisamos vencer. A vitória, entretanto, exige esforço permanente de aprimoramento intelectual, ético, estratégico e tático-operativo, em consonância com o projeto ético-político da profissão. Como o grande poeta Pablo Neruda, confiemos no glorioso "amanhã, que chegará com passos verdes, porque ninguém detém o rio da aurora”.

\author{
[...] o Serviço Social \\ pode dar uma \\ resoluta \\ contribuição à \\ história do ponto de \\ vista do trajeto \\ para a \\ emancipação \\ humana, quer seja \\ no ensino, na \\ pesquisa, na \\ extensão e no \\ exercício \\ profissional [...]
}


